\title{
Frontières
}

\section{Julie Durocher et Gabriel Jones, Enfermés dehors, Montréal, Stanké, 1999, 71 p.}

\section{Diane Laflamme}

Volume 14, numéro 1, automne 2001

URI : https://id.erudit.org/iderudit/1074170ar

DOI : https://doi.org/10.7202/1074170ar

Aller au sommaire du numéro

\section{Éditeur(s)}

Université du Québec à Montréal

\section{ISSN}

1180-3479 (imprimé)

1916-0976 (numérique)

Découvrir la revue

\section{Citer ce compte rendu}

Laflamme, D. (2001). Compte rendu de [Julie Durocher et Gabriel Jones, Enfermés dehors, Montréal, Stanké, 1999, 71 p.] Frontières, 14(1), 75-76. https://doi.org/10.7202/1074170ar

Ce document est protégé par la loi sur le droit d'auteur. L'utilisation des services d'Érudit (y compris la reproduction) est assujettie à sa politique d'utilisation que vous pouvez consulter en ligne.

https://apropos.erudit.org/fr/usagers/politique-dutilisation/
Cet article est diffusé et préservé par Érudit.

Érudit est un consortium interuniversitaire sans but lucratif composé de l’Université de Montréal, l'Université Laval et l'Université du Québec à Montréal. Il a pour mission la promotion et la valorisation de la recherche. https://www.erudit.org/fr/ 
Julie Durocher et Gabriel Jones

\section{Enfermés dehors}

Montréal, Stanké, 1999, 71 p.

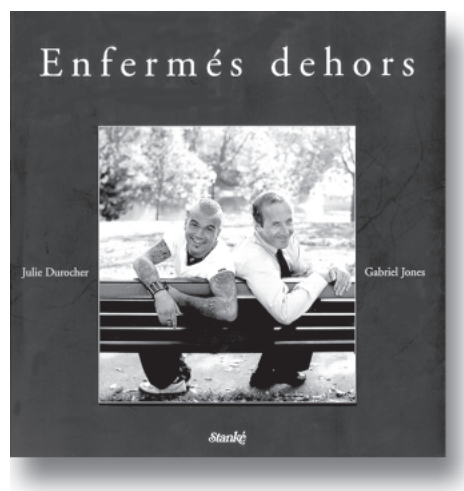

On voudrait trouver plus que des mots pour vraiment dire merci et bravo à Julie Durocher, à Gabriel Jones et à toutes les personnes qui ont rendu possible la publication de ce très beau livre. N'essayez même pas de résister aux deux sourires qui vous attendent en page couverture! Ce livre ne doit pas rester chez votre libraire : repartez avec lui, amenezle chez vous, il vous fera du bien... à l'âme.

Cette magie, ce sont des jeunes qui en sont capables. Des jeunes que vous ne connaissez pas encore mais qui vous deviendront très proches à mesure que vous les rencontrerez au fil des photos qui ont été rassemblées pour créer ce livre. Pour vous les présenter, des visages bien connus au Québec: des personnalités du monde de la télévision, du sport, de la mode, de l'écriture, des arts, du spectacle, de la politique... Le temps d'une photo, chacune de ces personnes que vous reconnaîtrez, qui vous inspire confiance, habite le même univers qu'un jeune de la rue: une jeune femme, un jeune homme dont vous hésiteriez probablement à vous rapprocher si votre regard n'était pas ainsi apprivoisé par la lentille du photographe. Oui, ce sont des jeunes de la rue qui feront ainsi irruption chez vous. Vous aurez chaud au cœur d'avoir le privilège de faire leur connaissance, l'espace d'un instant volé aux parcours programmés dont vous vous contentez le plus souvent et dont ils sont toujours les trouble-fête.

Comme le disent dans la préface ceux qui ont pris ces photos, Julie et Gabriel, "la présence de personnalités a pour but de provoquer. D'un côté la juxtaposition surprend, et de I'autre, on présente une image plus positive que celle qu'on est habitué à voir, bien qu'aussi réelle " (p. 7). Oui, il n'y a pas de doute, il est bien réel le rire que partagent ensemble Yvon Deschamps et Anick Primeau, l'élan enjoué qui emporte dans une même course, vers le fonds d'une ruelle grise de pluie, Macha Grenon et Julie Haché (p. 16, 17). Elle est bien réelle la douceur de vivre que partagent avec nous, sur une pellicule aux couleurs vibrantes, Isabel Richer et Daniel Cassivi (p. 27), André Melançon et Valérie Bouchard (p. 63). Vous ne pourrez pas rester insensible quand vous lirez au bas de la photo que Valérie n'est plus parmi nous. Vous regretterez aussi de ne pas avoir été invité-e à faire le voyage avec Michel Barette et Chico (p. 26) sous un ciel si bleu... peu importe si on se retrouve en panne.

Du réel, vous passerez à l'irréel: regardez bien en page 15 cette photo où Sébastien Jolicoeur et Margie Gillis semblent atterrir ensemble parmi nous, venus de loin, main dans la main... des anges qu'on espérait sans vraiment y croire? Laissez-vous habiter par le jeu des symétries entre les gens et les ombres (p. 8, 37), les gens et les architectures (p. 65, 66), les gens et les gens (p. 13, 48, 70). Applaudissez aux prouesses du photographe qui permettent à Robert Lepage de tenir dans sa main Andrée Desrosiers (p. 18), qui 
dédoublent Frank Laliberté et David LaHaye pour leur permettre à la fois de jaser sur un bout de trottoir et de partager, l'un envers l'autre, la plus superbe indifférence (p. 59).

Vous êtes-vous déjà demandé ce qu'on voit quand on est assis par terre, adossé au mur du métro? Vous le saurez grâce à Harris Hrvacic et à Patrice l'Écuyer, en page 39. Avez-vous déjà pensé, encore en les croisant dans le métro, qu'il était grand temps que tous ces jeunes marginaux s'intègrent enfin à notre belle et confortable société ? Pensez-y deux fois. Ne vaudrait-il pas mieux que nous apprenions ensemble, eux et nous, à " marcher sur les eaux " comme le font Marie-Josée Girard et Simon Chang (p. 69). C'est sûrement elle qui lui a montré comment faire ! Les jeunes trouvent des équilibres là où nos yeux trop compétents ne voient que vagues.

II y a aussi de beaux textes qui accompagnent ces photographies: des poèmes, une lettre qui s'adresse à maman, un autre pour papa. Celle ou celui qui ajoute ainsi quelques mots à notre intention, c'est parfois le jeune qui est là, sur la photo: Nicolas Bouchard, David ChampagneTurcotte, Puce, Frank Laliberté. II y a également des textes de Sol et de Gilles Vigneault, qui accompagnent la photo de leur rencontre avec Antoine Lafortune, avec Marie Desmeules. Les deux photographes, Julie et Gabriel, prennent aussi la parole.

Ne manquez pas ce rendez-vous. Ce serait trop grave... pour nous tous.

Diane Laflamme 